(1)

CrossMark

\title{
Dual intracavitary therapy for pleural infections: leaving reluctance behind
}

\author{
José M. Porcel (1) \\ Affiliation: Pleural Medicine Unit, Dept of Internal Medicine, Arnau de Vilanova University Hospital, IRBLleida, \\ Lleida, Spain. \\ Correspondence: José M. Porcel, Pleural Medicine Unit, Dept of Internal Medicine, Arnau de Vilanova \\ University Hospital, Avda Alcalde Rovira Roure 80, 25198 Lleida, Spain. E-mail: jporcelpayahoo.es
}

@ERSpublications

Intrapleural tPA/DNase therapy is cost-effective for the management of complicated parapneumonic effusions and empyemas http://bit.ly/2Lv0Kg9

Cite this article as: Porcel JM. Dual intracavitary therapy for pleural infections: leaving reluctance behind. Eur Respir J 2019; 54: 1901001 [https://doi.org/10.1183/13993003.01001-2019].

The optimal management of complicated parapneumonic effusions and empyemas remains undefined. Over the past two decades, three guidelines from scientific societies have been developed to aid treatment selection in this setting [1-3]. In 2000, the American College of Chest Physicians stated that intrapleural fibrinolytics, video-assisted thoracoscopic surgery (VATS) and surgery (thoracotomy with or without decortication) were all acceptable approaches for managing patients who meet any of the following characteristics [1]: pus (category 4 effusions or, strictly speaking, empyemas), large (at least half of the hemithorax) or loculated effusions, positive pleural fluid cultures or Gram stains, or a fluid $\mathrm{pH}<7.20$ (the last three conditions integrating category 3 effusions). However, the strength of these recommendations was low due to the existence at that time of only three randomised controlled trials totalling less than 100 patients. In 2010, the British Thoracic Society (BTS) updated its 2003 guidelines [2]. Intrapleural fibrinolytics were not routinely recommended for complicated pleural infections based on the results of the MIST1 trial [4], while a consultation with a thoracic surgeon was suggested in cases of inadequately drained fluids after 5 to 7 days of tube thoracostomy. The most recently published consensus guidelines from the American Association for Thoracic Surgery consider VATS as the first-line approach in all patients with acute empyema and, like BTS, discourage administration of fibrinolytics [3]. But, in light of current evidence, is it justified for surgery to have such a prominent role over intrapleural therapies in the treatment of pleural infections? In this author's view, certainly not.

Instillation of fibrinolytics through a chest catheter, formerly considered a modern and potentially effective therapy for empyemas, fell out of favour after the publication of the MIST1 [4] and MIST2 [5] randomised controlled trials. In these studies, streptokinase and alteplase (tPA), respectively, were not superior to placebo regarding the outcomes of mortality, referral for surgery, length of hospital stay and radiological improvement $[4,5]$. Notwithstanding, the rightful place of fibrinolytics is still debatable considering that a meta-analysis of 10 randomised trials, including both MIST1 and MIST2, supported their benefit in the reduction of surgical referral rates [6].

More importantly, MIST2 prompted a paradigm shift in the management of pleural infections, since the combination of intrapleural tPA and deoxyribonuclease (or DNase; an enzyme which reduces pus viscosity) was shown to significantly improve chest radiographic opacification, reduce need for surgery and shorten hospitalisation when compared with tPA and DNase individually or placebo [5]. Following this pivotal trial, other non-randomised studies have further supported the benefits of the tPA/DNase 
combination. Overall, the sum of 11 series [5, 7-16], totalling 642 patients with pleural infections $(42 \%$ with empyemas) who were treated with intrapleural tPA plus DNase, shows that $87 \%$ were cured without a rescue surgical intervention. Specifically, in the MIST2 trial only two of 48 patients (4\%) failed tPA/DNase therapy and required surgery [5]. This therapy is safe, with a mean rate of non-fatal pleural bleeding lower than $4 \%$ [17].

In addition to the limited sample of patients in the combination arm of MIST2 [5] and the satisfactory experience of some groups using fibrinolytics alone [18], the routine recommendation of dual intrapleural therapy has met resistance owing to financial reasons. In truth, tPA/DNase is viewed as a costly therapy mainly due to its tPA component. In this issue of the European Respiratory Journal, LuENGo-FernANDEZ et al. [19] dispel the economic concerns of this treatment modality. The authors calculated costs associated with initial and subsequent hospitalisations, surgery and intrapleural medications that were collected alongside the MIST2 trial. In so doing, they retrospectively estimated the cost-effectiveness of the tPA/ DNase combination compared to tPA or DNase alone or placebo over a 1-year period. The analysis of 178 patients showed a nonsignificant trend towards a lower total number of days in hospital in the tPA/DNase group (relative reduction of $31 \%, 59 \%$ and $54.5 \%$ against tPA, DNase and placebo groups, respectively). Costs and one life-year gained did not differ significantly between groups. However, given the willingness to pay a threshold of EUR 34220 per life-year gained (i.e. the maximum value at which the National Institute of Health and Care Excellence consider an intervention to be cost-effective), there was an $86 \%$ chance that tPA would be cost-effective when compared to the other treatment branches [19]. Even so, as a secondary analysis of the MIST2 trial, this study was not designed to detect meaningful differences in healthcare costs. Moreover, the ideal scenario for conducting cost-effectiveness analyses is when costs and outcome measures (e.g. life-years or quality-adjusted life-years gained) are collected prospectively in a controlled setting. Despite these limitations, the current study provides evidence to support the cost-effectiveness of dual intrapleural therapy, while awaiting future confirmatory trials.

The economic analysis by Luengo-Fernandez et al. [19] was based on the dosing regimen used in the MIST2 trial, namely, $5 \mathrm{mg}$ of DNase and $10 \mathrm{mg}$ of tPA, each given twice daily for 3 days [5]. It should be highlighted, however, that these intrapleural drug doses were chosen in an entirely empirical way. For example, $85 \%$ of pleural infections in 25 horses solved with a median of two doses of just $3.75 \mathrm{mg}$ tPA [20]. Since Equidae have an average weight 4 to 10 times higher than humans, it is plausible to speculate that lower doses of fibrinolytics can also be effective in the latter [21]. In fact, a number of drug regimen variations with an apparently similar efficacy to the original MIST2 protocol have been reported through small observational and mostly retrospective studies: concurrent rather than sequential administration of drugs [10, 12, 14], halving of the tPA dose [13], once daily application of the dual therapy [8] or, when necessary, extension of the regimen beyond 3 days [9]. Additionally, whether urokinase or new fibrinolytics, such as single chain urokinase plasminogen activator (scuPA) [22], may replace tPA in dual intrapleural regimens has not yet been tested. Individualised dosages of fibrinolytics based on pleural fluid plasminogen activator activity is an attractive notion that needs to be explored [23]. If the classical MIST2 protocol is truly cost-effective, then the application of more simplified administration protocols will be even more so.

In summary, intrapleural fibrinolytic and DNase therapy not only removes the need for surgery in most cases, but it also seems to be cost-effective. Thus, it is time to overcome the reluctance that this medical approach may still have. According to current evidence, it is reasonable to suggest that the classification of an empyema as a predominantly surgical disease will soon come to an end. Hopefully, the question of whether or not the intrapleural fibrinolytic/DNase combination represents an equal or better alternative to early VATS will eventually be answered by the ongoing MIST3 trial.

Conflict of interest: None declared.

\section{References}

1 Colice GL, Curtis A, Deslauriers J, et al. Medical and surgical treatment of parapneumonic effusions: an evidence-based guideline. Chest 2000; 118: 1158-1171.

2 Davies HE, Davies RJ, Davies CW, et al. Management of pleural infection in adults: British Thoracic Society Pleural Disease Guideline 2010. Thorax 2010; 65: Suppl. 2, ii41-ii53.

3 Shen KR, Bribriesco A, Crabtree T, et al. The American Association for Thoracic Surgery consensus guidelines for the management of empyema. J Thorac Cardiovasc Surg 2017; 153: e129-e146.

4 Maskell NA, Davies CW, Nunn AJ, et al. U.K. controlled trial of intrapleural streptokinase for pleural infection. N Engl J Med 2005; 352: 865-874.

5 Rahman NM, Maskell NA, West A, et al. Intrapleural use of tissue plasminogen activator and DNase in pleural infection. N Engl J Med 2011; 365: 518-526.

6 Nie W, Liu Y, Ye J, et al. Efficacy of intrapleural instillation of fibrinolytics for treating pleural empyema and parapneumonic effusion: a meta-analysis of randomized control trials. Clin Respir J 2014; 8: 281-291. 
7 Piccolo F, Pitman N, Bhatnagar R, et al. Intrapleural tissue plasminogen activator and deoxyribonuclease for pleural infection. An effective and safe alternative to surgery. Ann Am Thorac Soc 2014; 11: 1419-1425.

8 Mehta HJ, Biswas A, Penley AM, et al. Management of intrapleural sepsis with once daily use of tissue plasminogen activator and deoxyribonuclease. Respiration 2016; 91: 101-106.

9 McClune JR, Wilshire CL, Gorden JA, et al. Safety and efficacy of intrapleural tissue plasminogen activator and DNase during extended use in complicated pleural space infections. Can Respir J 2016; 2016: 9796768.

10 Majid A, Kheir F, Folch A, et al. Concurrent intrapleural instillation of tissue plasminogen activator and DNase for pleural infection. A single-center experience. Ann Am Thorac Soc 2016; 13: 1512-1518.

11 Majid A, Ochoa S, Chatterji S, et al. Safety and efficacy of tissue plasminogen activator and DNase for complicated pleural effusions secondary to abdominal pathology. Ann Am Thorac Soc 2017; 14: 342-346.

12 Bishwakarma R, Shah S, Frank L, et al. Mixing it up: coadministration of tPA/DNase in complicated parapneumonic pleural effusions and empyema. J Bronchology Interv Pulmonol 2017; 24: 40-47.

13 Popowicz N, Bintcliffe O, De Fonseka D, et al. Dose de-escalation of intrapleural tissue plasminogen activator therapy for pleural infection. The Alteplase Dose Assessment for Pleural Infection Therapy Project. Ann Am Thorac Soc 2017; 14: 929-936.

14 Kheir F, Cheng G, Rivera E, et al. Concurrent versus sequential intrapleural instillation of tissue plasminogen activator and deoxyribonuclease for pleural infection. J Bronchology Interv Pulmonol 2018; 25: 125-131.

15 Innabi A, Surana A, Alzghoul B, et al. Rethinking the doses of tissue plasminogen activator and deoxyribonuclease administrated concurrently for intrapleural therapy for complicated pleural effusion and empyema. Cureus 2018; 10: e2214.

16 Khemasuwan D, Sorensen J, Griffin DC. Predictive variables for failure in administration of intrapleural tissue plasminogen activator/deoxyribonuclease in patients with complicated parapneumonic effusions/empyema. Chest 2018; 154: 550-556.

17 Porcel JM. Minimally invasive treatment of complicated parapneumonic effusions and empyemas in adults. Clin Respir J 2018; 12: 1361-1366.

18 Alemán C, Porcel JM, Alegre J, et al. Intrapleural fibrinolysis with urokinase versus alteplase in complicated parapneumonic pleural effusions and empyemas: a prospective randomized study. Lung 2015; 193: 993-1000.

19 Luengo-Fernandez R, Penz E, Dobson M, et al. Cost-effectiveness of intrapleural use of tissue plasminogen activator and DNase in pleural infection: evidence from the MIST2 randomised controlled trial. Eur Respir J 2019; 54: 1801550

20 Tomlinson JE, Byrne E, Pusterla N, et al. The use of recombinant tissue plasminogen activator (rTPA) in the treatment of fibrinous pleuropneumonia in horses: 25 cases (2007-2012). J Vet Intern Med 2015; 29: 1403-1409.

21 Hart JA, Badiei A, Lee YCG. Successful management of pleural infection with very low dose intrapleural tissue plasminogen activator/deoxyribonuclease regime. Respirol Case Rep 2019; 7: e00408.

22 Beckert L, Brockway B, Simpson G, et al. Phase 1 trial of intrapleural LTI-01; single chain urokinase in complicated parapneumonic effusions or empyema. JCI Insight 2019; 5: 127470.

23 Idell S, Florova G, Shetty S, et al. Precision-guided, personalized intrapleural fibrinolytic therapy for empyema and complicated parapneumonic pleural effusions: the case for the fibrinolytic potential. Clin Pulm Med 2017; 24: $163-169$ 